\title{
A depressão infantil e suas formas de manifestação
}

\author{
Infantile depression and its ways of manifestation
}

\author{
Joseane Huttel ${ }^{[a]}$, Karina Alzira Kisxiner ${ }^{[b]}$, Rodrigo Alexandre Bonetti ${ }^{[c]}$, \\ Miriam Izolina Padoin Dalla Rosa ${ }^{[\mathrm{d}]}$
}

[a] Discente de Psicologia da Universidade Paranaense (UNIPAR), Cascavel, PR - Brasil, e-mail: josihutel08@hotmail.com

[b] Discente do quarto ano de Psicologia da Universidade Paranaense(UNIPAR), Cascavel, PR - Brasil, e-mail: josihutel08kahkisxiner@hotmail.com

[c] Discentedoquarto anodePsicologia daUniversidadeParanaense(UNIPAR),Cascavel,PR-Brasil, e-mail:josihutel08bonettirodrigo@hotmail.com

[d] Mestre em Educação pela Universidad Autónoma de Asunción (UAA/PY), orientadora psicóloga, docente da Universidade Paranaense (UNIPAR), Toledo, PR - Brasil, e-mail: dallarosa@unipar.br

\section{Resumo}

O estudo da depressão infantil ainda é muito recente, seus estudos só se destacaram a partir da década de 70, onde os estudiosos e pesquisadores começaram a investigar a depressão no cenário infantil. A depressão se apresenta hoje como o mal da virada do século e esta pesquisa se torna então relevante no sentido que possibilita maior aproximação, reunião do material e esclarecimento, no caso específico da depressão infantil. O presente estudo visa a identificar a concepção do conceito de depressão infantil dentre os fundamentos teóricos da psicologia e reunir dados referentes a essa patologia, analisar as formas de manifestação da depressão em crianças com até cinco anos de idade e a relação entre essa criança e o adulto. Trata-se de uma pesquisa qualitativa realizada no período do mês de agosto. Para levantamento de dados se utilizou de questionários do tipo aberto, contendo quinze perguntas, para uma amostra de 20 psicólogos clínicos, de ambos os sexos, escolhidos aleatoriamente nas cidades de Cascavel, Corbélia, Realeza e Toledo. A análise e a discussão dos dados demonstraram que há a necessidade de maior discussão e apropriamento do assunto depressão infantil, que os psicólogos em sua maior parte comungam com os postulados teóricos e que há um baixo número de crianças sendo diagnosticadas como depressivas.

Palavras-chave: Criança. Depressão infantil. Abordagens teóricas. 


\begin{abstract}
The study on infantile depression is still very recent; its studies were only highlighted from the seventies on, when the students and researchers started to investigate the depression in the infantile context. The depression presents itself today as the evil from the turn of the century so this research becomes relevant in the sense that it makes possible a bigger approximation, data gathering and enlightenment on the matter of infantile depression. This article aims to identify the birth of the concept of infantile depression within the theoretical fundaments of Psychology and to gather data related to this pathology, analyze the ways the depression of children up to five years old is manifested and the relation between infantile and adult depression. This research is qualitative, and it has been performed in the period of August. To gather data, questionnaires (open, containing fifteen questions, for a sample of twenty clinic psychologists, man and woman, randomly chosen in the cities of Cascavel, Corbélia, Realeza and Toledo) were used. The analysis and discussion of the data showed that there is the necessity of a bigger understanding and discussion on the subject of infantile depression, the psychologists, in their whole part, should follow the theoretical postulates and that there is a low number of children being diagnosed as depressives.
\end{abstract}

Keywords: Children. Infantile depression. Theoretical approaches.

\section{Introduçáo}

O presente estudo é fruto de uma revisão de literatura e de pesquisa de campo do tipo qualitativa. Seu objetivo é identificar a concepção do conceito de depressão infantil dentre os fundamentos teóricos da psicologia, analisar as formas de manifestação da depressão em crianças até cinco anos e investigar a correlação entre depressão infantil e adulta. A depressão apresenta-se hoje como o mal da virada do século e que, segundo a Organização Mundial da Saúde, em 2020 será a segunda moléstia que mais roubará tempo de vida útil da população. Esta pesquisa é relevante no sentido em que possibilita uma maior aproximação, reunião do material e esclarecimento, no caso específico da depressão infantil. Este trabalho discute o termo depressão, a depressão infantil, as principais características da depressão infantil, fatores de risco, comorbidades presentes na depressão infantil, o diagnóstico e as diferentes abordagens teóricas da depressão.

O termo "depressão", segundo Rodrigues (2000), que em grego se escreve deprimere - de (baixar) e premere (pressionar), significa "pressão baixa". É um termo relativamente recente, que somente foi introduzido no debate sobre melancolia em contextos médicos apenas no séc. XVIII.

De acordo com Guertzenstein (1989), citado por Buzaid, Cunha, Romano e Watanabe, (2005), os primeiros relatos de transtornos patológicos de humor surgiram na Bíblia, no livro de Job (1500 a.C.). Porém, as primeiras referências clínicas e doutrinárias encontram-se nos escritos de Hipócrates
(460-370 a.C.). Muitos estudiosos, como Arateus (início do séc. I a.C.), Galeno (séc. II da era cristã), Plutarco (séc. II d.C.), Pinel (séc. XVIII), Griesinger, Falret e Baillarger e Kraepelin (séc. XIX), também relataram os sintomas da melancolia e da depressão.

Para Lage e Monteiro (2007), a implantação do termo depressão se deu por via da relação com a melancolia, passando a ser utilizado, inicialmente, durante o século XIX. A melancolia, na antiguidade, não era associada diretamente a uma ideia de doença, pelo contrário, sempre teve sua descrição relacionada a um traço de superioridade intelectual e refinamento social. No final do século XVIII, Philipe Pinel empreendeu a primeira tentativa de categorização psiquiátrica acima da melancolia, sua pesquisa baseava-se na observação e agrupamento dos sintomas. Esquirol, seu discípulo, mais tarde empenhou-se em desenvolver descrições mais detalhadas e acabou por defini-la como um quadro comportamental de tristeza, abatimento, desgosto de viver, que se faz acompanhar de um delírio ou ideia fixa. Foi Emil Kraeplin, o autor do primeiro Compêndio de psiquiatria, que fez com que o termo melancolia caísse gradativamente no esquecimento, quando em 1983 ofereceu uma definição baseada principalmente no quadro clínico da psicose maníaco-depressiva, cuja característica foi descrita como uma alternância de acessos depressivos.

Assunção (1992) assinala que desde meados do século XVIII a depressão tem sido encontrada tanto em crianças como em adolescentes. No entanto, até a década de 1960, a depressão infantil não era contemplada como alteração. Foi a partir da década de 70 que 
aumentou o interesse no campo de investigação, e no meio acadêmico, onde houve uma maior abrangência sobre o tema (Nakamura \& Santos, 2007).

De acordo com Bahls (2002), o Instituto Nacional de Saúde Mental dos EUA (NIMH) só reconheceu a depressão em crianças e adolescentes a partir de 1975 , e o interesse sobre o assunto tem sido crescente. Atualmente existem duas linhas de pensamento para caracterizar a depressão em crianças, sendo uma delas de caráter unicista, em que a enfermidade seria igual entre as crianças, os adolescentes e os adultos, utilizando-se do DSM-IV e CID-10 como forma de diagnóstico dessa patologia, e a outra que valoriza a maturidade da criança para referir-se aos sintomas da depressão infantil. Para Fichtner, (1997), os episódios depressivos na infância incidem na mesma proporção que em adultos.

Posnaski e Petti (1983), citados por Barbosa e Lucena, (1995), ao contrário, afirmam que a depressão infantil pode aparecer antes dos seis anos e seus sintomas e características são próprios da infância. A depressão no adulto e na criança não é comparável, pelo contrário, trata-se de entidades psiquiátricas completamente diferentes. Os sintomas são similares, más o processo subjacente é diferente. O presente estudo trabalhará com a segunda linha de pensamento, tendo em vista que a maioria dos autores na área da depressão a defendem e chamam a atenção para a importância do processo de surgimento de comportamentos e sintomas depressivos, havendo uma sintomatologia predominante por faixa etária.

\section{Depressáo infantil}

Andriola e Cavalcante (1999) destacam que, apesar de não existir uma definição consensual sobre a depressão infantil, o que se pode afirmar é que se trata de uma perturbação orgânica que engloba variáveis biopsicossociais. Da perspectiva biológica, essa patologia é encarada como uma provável disfunção dos neurotransmissores graças à herança genética, à anormalidade e/ou a falhas em áreas cerebrais específicas. Do ponto de vista psicológico, a depressão pode estar associada a alguns aspectos comprometidos da personalidade, ausência de autoconfiança e baixa autoestima. Do ponto de vista social, pode ser postulada como uma inadaptação ou pedido de socorro, podendo ser consequência de aspectos culturais, familiares ou escolares.
Para Bahls (2002), o primeiro episódio tem duração de cinco a nove meses e os sintomas podem ser recorrentes e se estenderem até a idade adulta, representando uma alta vulnerabilidade para os transtornos depressivos. São considerados fatores preditores de recorrência: início precoce, gravidade do episódio, presença de sintomas psicóticos, presença de estressores, episódios anteriores, comorbidade e ausência de tratamento. Kovacs et al. (1984), citados por Bahls, (2002), afirmam que $74 \%$ das crianças apresentam melhora significativa dentro de um ano, e $92 \%$ se recuperam em um período de dois anos. Porém, eles também afirmam que após a recuperação costuma permanecer algum grau de prejuízo psicossocial, e quanto mais precoce for o aparecimento da patologia maior tenderá a ser o prejuízo.

Fichtner (1997) aponta que o prejuízo no desenvolvimento infantil acarretado pela depressão infantil pode ser em nível físico, cognitivo, psicomotor e psicossocial, afetando principalmente as habilidades necessárias para a aprendizagem. Além disso, afeta também a família e o grupo em que a criança está inserida (Calderano \& Carvalho, 2005).

Segundo Calderano e Carvalho (2005), as crianças depressivas envolvem-se, normalmente, em situações que ofereçam perigo à sua integridade física. $\mathrm{Na}$ maioria das vezes têm consciência do perigo, no entanto, conflitos inconscientes predominam e levam-na a emitir determinados comportamentos de risco, numa tentativa de mobilizar a atenção das pessoas para que percebam o seu sofrimento. As crianças são igualmente pessoas que apresentam o desespero como contraponto às suas amarguras existenciais. A questão mais importante é analisar a intencionalidade dessas crianças quanto à própria destruição do que negar a tentativa de suicídio. "É comum atribuir-se a possíveis acidentes os determinantes que provocam a hospitalização desses pacientes. Então, são descritos como acidentes o manuseio com armas de fogo, quedas de grandes alturas" (Angerami-Camon, 2004, p. 110-111).

Para Barbosa e Lucena (1995), crianças depressivas têm dificuldades para entender explicações e concentrar-se, pois quando o emocional está comprometido há interferências nas questões cognitivas. De acordo com Buzaid et al. (2005), há a retração do eu na experiência depressiva, independente do momento de vida em que ela ocorre. Com essa retração, ocorre a diminuição do contato com o ambiente, a qual se manifesta pelo desinteresse, falta 
de reatividade, anedonia e fadiga constante, o que leva ao estreitamento e à limitação dos horizontes, pois o indivíduo depressivo afasta-se do convívio com os outros.

\section{Principais características da depressão}

Andriola e Cavalcante (1999) e Barbosa e Lucena (1995) apontam como principais comportamentos que caracterizam a depressão infantil: sintomas físicos (dores de cabeça e abdominais, fadiga e tontura), seguidos por ansiedade, fobias, agitação psicomotora ou hiperatividade, irritabilidade, diminuição do apetite, alteração do peso e com menor frequência a ocorrência de enurese e encoprese, fisionomia triste, comunicação deficiente, choro frequente, movimentos repetitivos e auto e heteroagressividade na forma de comportamento agressivo e destrutivo, autodepreciação, distúrbio do sono, diminuição da socialização, modificação de atitudes em relação à escola, perda de energia habitual, tristeza, humor disfórico, retardo psicomotor, pesadelos, terror noturno, ansiedade de separação, diminuição da capacidade cognitiva e perda de interesse pelas atividades prazerosas dessa etapa da vida. As crianças deprimidas não conseguem rir, brincar ou brigar, por isso são consideradas enfermas, além disso, são tímidas e evitam estar com outras pessoas.

Fichtner (1997) apresenta diferentes formas de manifestações depressivas e os chamados distúrbios com déficits de atenção e hiperatividade. As crianças depressivas podem apresentar as seguintes características: pouca agressividade, baixo desempenho escolar, passividade, altos níveis de desatenção, baixa autoestima, apatia (fuga ao desafio). Também apresentam sentimentos de culpa, desabilidades motoras e são inábeis para o esporte. Em outros casos, apresentam características antagônicas, tornando-se agressivas, hiperativas, negativistas e apresentando sérios problemas de conduta.

\section{Fatores de risco}

Conforme Calderano e Carvalho (2005), alguns fatores influenciam de forma direta no aparecimento de depressão em criança, tais como: hereditariedade, condições sociais, configuração familiar, a função materna, o início do funcionamento psíquico e o superego.

Bahls (2002) reconhece que a presença de depressão em um dos pais aumenta em até três vezes o risco de aparecimento na criança, seguido por estressores ambientais, como abuso físico e sexual e perda de um dos pais irmão ou amigo íntimo. Calderano e Carvalho (2005) afirmam que a doença psíquica de um dos pais constitui 43\% de chance de ocorrer em seu filho e geralmente filhos de pais depressivos tendem a desenvolver o mesmo mal, além de outros transtornos de ordem mental e distúrbios de conduta. A hereditariedade pode ser um fator importante, mas não determinante único no aparecimento da patologia, e para melhorar a saúde mental do filho é importante tratar primeiramente os pais e trabalhar com tentativas de mudança no padrão familiar. Milavic (1985), citado por Andriola e Cavalcante (1999), aponta que crianças que possuem pais depressivos podem ser mais propensas a desenvolver a depressão, pois além da provável imitação dos comportamentos depressivos dos pais, há também a possibilidade da herança genética.

O fator constitucional da criança, como o comportamento dos pais, são determinantes dos problemas psiquiátricos das crianças. Um comportamento parental impróprio pode afetar uma criança em diversos níveis. Um controle excessivo pode levar a uma inibição, repressão e aumento da auto crítica, um pai inadequado pode ter dificuldade em estimular o filho a demonstrar afeto. Os pais que são prejudicados por problemas psiquiátricos têm menos probabilidade de ensinar comportamentos adequados a seus filhos (Assumpção Jr., 1996, p. 111).

Milavic também afirma que as manifestações depressivas que configuram um quadro clínico, no desenrolar dos primeiros anos de vida, estão amplamente ligadas com os transtornos do vínculo mãe/filho, o abandono infantil, a privação materna e a psicopatologia dos pais.

Para as crianças, a privação de relações objetais no primeiro ano de vida é um fator muito prejudicial, que leva a sérios distúrbios emocionais. Quando isso ocorre, as crianças apresentam um quadro clínico impressionante, parecem 
ter sido privadas de algum elemento vital a sobrevivência (Spitz, 2004, p. 211-212).

Segundo Fichtner (1997), a psicopatologia dos pais, vivenciada pela criança como rejeição ou privação parcial, pode mobilizar reações depressivas em bebês. No entanto, um precoce e satisfatório relacionamento materno/filial protege a criança contra a depressão, ajudando-a a elaborar as fases depressivas do próprio desenvolvimento. A criança organiza as bases da segurança, de confiança e de apego aos pais e a outras pessoas, bem como estimula a capacidade de adequar suas reações emocionais, podendo explorar o mundo externo e as situações novas sem tensão e com prazer.

Segundo Calderano e Carvalho (2005), um ambiente familiar saudável, é capaz de suprir as necessidades básicas, como acolhimento e proteção, proporcionando à criança um desenvolvimento emocional saudável. Quando esse ambiente é inexistente, a criança se utiliza de mecanismos específicos para lidar com as dificuldades, comprometendo, dessa forma, o desenvolvimento das estruturas de personalidade que estão se formando na infância. Buzaid et al. (2005) postulam que determinadas doenças, enfermidades crônicas, intervenções cirúrgicas, enfermidades crônicas dos pais, instabilidade da convivência familiar e disputas familiares podem levar a um quadro depressivo na criança. Quanto às condições sociais e familiares, Calderano e Carvalho (2005) ainda afirmam que as pessoas que vivem em condições socioeconômicas desfavoráveis são mais propensas a desenvolver patologias físicas e mentais. Habitualmente nessas famílias de baixa renda, a figura masculina ocupa lugar secundário, o desemprego é elevado, há uniões transitórias entre os casais, e o alcoolismo e a violência se encontram presentes. Ainda, segundo o mesmo autor, as crianças nesse contexto sofrem consequências diretas dessa desestruturação, uma vez que não têm assegurada a condição básica necessária para um bom desenvolvimento.

De acordo com Fichtner (1997), outros dois fatores de risco para o surgimento da depressão infantil são as situações traumáticas desencadeadas por intensificação do estresse ou por perdas significativas. Em geral, não apresentam antecedentes de depressão familiar. O surgimento de um acontecimento ou evento estressante pode desestruturar o comportamento infantil, levando a criança a ter sentimentos e pensamentos depressivos. A esses acontecimentos ou eventos dá-se o nome de fatores estressantes.

Bowlby (1998) aponta que na maioria dos distúrbios depressivos a principal questão a ser observada é a capacidade de estabelecer e manter relações afetivas. O sentimento de desamparo pode, nesse caso, ser atribuído às experiências vividas pela pessoa em sua família de origem. Essas experiências são de três tipos correlatos ou de uma combinação deles. É possível que a pessoa tenha passado pela experiência de nunca ter estabelecido uma relação estável e segura com seus pais. E essas experiências infantis fazem com que ela desenvolva uma acentuada tendência a interpretar qualquer perda como mais um de seus fracassos em estabelecer e manter uma relação afetiva estável. Pode ser que tenham dito à pessoa que ela era indigna de ser amada, ou inconveniente, e/ ou incompetente. Sempre que uma pessoa assim sofre uma adversidade, longe de achar que as pessoas podem ajudá-la, espera delas hostilidade e rejeição. Ou mesmo, essa pessoa provavelmente tenha sofrido a perda de um dos pais durante a infância, acarretando-lhe consequências que, por mais desagradáveis que tenham sido, foram importantes para modificar seu comportamento.

\section{Comorbidades presentes na depressáo}

De acordo com Bahls (2002), a depressão infantil costuma apresentar altas taxas de comorbidade, as mais comuns são: transtorno de ansiedade, de conduta, desafiador opositivo e de déficit de atenção. O aparecimento desses transtornos aumenta a severidade da depressão, assim como sua presença costuma indicar uma evolução mais grave e um prognóstico mais pobre. Fichtner (1997) postula que existem manifestações de depressão mascarada que podem ser identificadas por meio de sintomas psicofisiológicos, como perda de apetite, dor de cabeça, alergias, asma e encoprese. A separação dos pais, a perda de pessoas queridas, e outras situações de perda, podem desencadear tristeza e sintomatologias próprias da depressão reativa.

Calderano e Carvalho (2005) apontam para a dificuldade em diagnosticar essa patologia, tendo em vista a presença dessas comorbidades, pois muitas vezes seus sintomas se manifestam de forma mascarada, por meio de de transtorno de déficit de 
atenção e hiperatividade, baixa autoestima, tristeza, medo, distúrbios do sono e baixo rendimento escolar. Por isso, muitas crianças não conseguem nomear e identificar os sintomas que lhe aparecem, pois aparecem de maneira multifacetada.

Ao examinar a criança, nem sempre a encontramos referindo sintomas que descrevam seu estado interno, com freqüência, relata somente tristeza ou solidão, de modo pouco claro e inespecífico, isso em função da dependência de seu funcionamento cognitivo para a identificação dos próprios sentimentos. Assim, grandes variedades de termos devem ser utilizados para que seja maximizada a possibilidade de que a criança, com idade menor, tenha seus sentimentos e vivências compreendidos (Assumpção Jr. \& Kuczynski, 2004, p. 63).

Os pediatras normalmente são procurados pelos pais por problemas que à primeira vista não são diagnosticados como depressão. As principais queixas orgânicas são: cefaleia, dores abdominais e diarreia, aparecem também a falta de apetite ou apetite exagerado, insônia, irritabilidade, agressividade ou passividade exagerada, choro sem razão aparente, dificuldades cognitivas, comportamento antissocial, ideias ou comportamentos suicidas. Porém é importante estar atento para o fato de que nem sempre os sintomas são indicadores de uma depressão mascarada (Calderano \& Carvalho, 2005).

\section{O diagnóstico e sua importância para o tratamento}

Barbosa e Lucena (1995) destacam que o diagnóstico, para os familiares da criança, é de extrema relevância. A depressão pode acarretar problemas no comportamento da criança, variando desde extrema irritabilidade à obediência excessiva, podendo ocorrer uma instabilidade significativa com relação a esses comportamentos. Andriola e Cavalcante (1999) atentam para o fato de que o diagnóstico precoce é imprescindível para o tratamento e para a mudança de comportamento mais rápida.

Os sintomas variam de acordo com a faixa etária da criança e, como ela ainda não é capaz de descrever seus sentimentos verbalmente, é necessário observar as formas de comunicação pré-verbal, tais como a expressão facial, produções gráficas e súbitas mudanças de comportamentos e postura corporal. Os sinais da presença da depressão em crianças são variados. É necessário analisar sua conjunção e a durabilidade dos episódios e não somente olhá-los isoladamente, afirmam Calderano e Carvalho (2005).

Para Amaral e Pereira (2004), o diagnóstico da depressão infantil ainda é difícil de ser feito, tendo em vista as suas variáveis funcionais, e a justaposição que apresenta com outras psicopatologias da infância e as diversas classes de depressão existentes. E, segundo Andriola e Cavalcante (1999), é preciso ficar alerta para o fato de que quanto mais problemas de comportamento a criança apresentar maior será a probabilidade de um desenvolvimento atípico, já que a depressão infantil pode estar interferindo nas atividades associadas à cognição e à emoção. Quando tal criança não é tratada a tempo, poderá desenvolver padrões de comportamento que se tornam resistentes a mudanças.

\section{As diferentes abordagens teóricas da depressão}

\section{Psicanálise}

O diagnóstico da depressão em psicanálise e em psiquiatria não é realizado da mesma forma. $\mathrm{O}$ termo depressão está vinculado à psiquiatria e não à psicanálise. Na psicanálise, o diagnóstico é diferencial, os termos utilizados são neurose, psicose e perversão. E o que se denomina depressão - na psicologia - é compreendido como sintoma em relação às perdas na psicanálise. Tais perdas, nesta abordagem, são entendidas como inerentes à condição humana.

De acordo com Rodrigues (2000), quando se investiga o tema da depressão na obra freudiana, é notável a não existência de uma teoria já estabelecida sobre o tema tal como ocorre com conceitos como o inconsciente, a transferência e a histeria. Isso porque o conceito de depressão, tal como concebido atualmente, não existia há cem anos, mas há importantes indicadores que permitem extrair conclusões sobre o tema. O mesmo autor defende o fato de Freud ter identificado e descrito fenômenos depressivos nas diversas categorias nosográficas, porém, não os reuniu à melancolia, como nos atuais manuais psiquiátricos, e sim os concebeu como próprios do existir humano. 
Freud (1986), no texto Luto e melancolia, de 1915, descreve a problemática pontuando que, se em alguns a perda leva à elaboração de um luto, em outros conduz aos precipícios da melancolia, pois as características distintivas são as mesmas encontradas no estado normal de luto, à exceção de uma: no luto, é possível ter certeza de qual objeto foi perdido; na melancolia, a perda objetal é retirada da consciência e recai sobre o próprio ego.

Esses estados obsessivos de depressão que se seguem à morte de uma pessoa amada revelamnos o que o conflito devido à ambivalência pode alcançar por si mesmo quando também não há uma retração regressiva da libido. $\mathrm{Na}$ melancolia, as ocasiões que dão margem à doença vão, em sua maior parte, além do caso nítido de uma perda por morte, incluindo as situações de desconsideração, desprezo ou desapontamento, que podem trazer para a relação sentimentos opostos de amor e ódio, ou reforçar uma ambivalência já existente (Freud, 1986, p. 256).

Dessa forma, a depressão deve ser concebida como luto, indicando também uma definição mais precisa para se detectar, na melancolia, uma alteração psíquica importante e, portanto, os termos depressão e luto são aqui compreendidos como equivalentes. Assim, baseando-se nesse posicionamento, reserva-se, para a melancolia, a indicação de formas mais severas de inibição motora e afetiva, assimbolia, nas quais pode ocorrer a alternância de episódios maníacos e de paralisia, e, para a depressão, indicar-se-ão quadros clínicos bem definidos de neurose ou sintomas que se apresentem nas mais diversas neuroses, onde a elaboração dos lutos aí está colocada. Todavia, é exatamente em torno da falta, da perda do objeto, que a estruturação do sujeito é norteada, levando, assim, o luto a ocupar um lugar central e, na medida em que se correlaciona com a questão dos sintomas depressivos e da melancolia, observa-se uma tendência à depressão dentro da própria constituição humana. Assim, a depressão não deve ser caracterizada enquanto estrutura psíquica por se tratar de um estado próprio para a constituição do aparelho psíquico, possibilitando declarar que tal quadro caracteriza o humano (Lage \& Monteiro, 2007).
Nesse contexto, Miller (1987) traz um dado importante ao afirmar que a demanda trazida por um paciente em psicanálise deve partir de um ideal, uma exigência, e principalmente partir do próprio paciente, a partir do desconforto de tipo especial que lhe causa o seu sintoma. E o sintoma não é o mesmo que no campo psiquiátrico, que é construído pelo próprio psiquiatra ou por seus manuais. $\mathrm{Na}$ psicanálise, o sintoma é descrito pelo paciente, no endereçamento do discurso do paciente ao analista.

Quinet (1993) diz que o diagnóstico diferencial só se coloca em psicanálise como função da direção da análise, só tem sentido se servir de orientação para a condução da análise e é buscado no plano simbólico, onde são articuladas as funções fundamentais do sujeito, e é por meio desse simbólico que se pode fazer o diagnóstico diferencial, por meio dos três modos de negação, correspondentes às três estruturas clínicas: perversão, neurose, psicose.

Portanto, as entrevistas preliminares são fundamentais para o diagnóstico em psicanálise. Segundo Quinet (1993, p. 31), as primeiras entrevistas possuem três funções: sintomal, diagnóstica e transferencial. Ou seja, em cada caso é preciso avaliar os sintomas que são próprios de cada pessoa, seja criança ou adulto, uma vez que não há tipos de diagnóstico diferentes entre crianças e adultos para a psicanálise. Nos dois casos, o que se leva em conta são as manifestações do inconsciente.

\section{Existencialismo fenomenológico}

Segundo Erthal (1991), para os existencialistas não existe uma teoria geral que seja capaz de explicar a patologia da conduta, até porque isso viria a se opor aos princípios filosóficos propostos, que conceituam o indivíduo como uma pessoa concreta, única, livre e realizadora de si mesma, rebelde, portanto, a enquadramentos diagnósticos. Os existencialistas se preocupam mais em "descobrir" o molde sobre o qual o cliente se criou do que impor-lhe um padrão. Ainda, segundo o mesmo autor, o existencialismo acredita sim que todos são um pouco “insanos", porém não nega a existência dos diferentes modos de ser-no-mundo e, acima de tudo, questiona qual o propósito do ato classificatório, que muitas vezes é um ato desumano e impossível de lidar com os problemas existenciais do ser humano. 
Tenório (2003) também afirma que o existencialismo fenomenológico compreende o sujeito como um ser livre, inserido em um mundo dotado de sentido particular, aberto às suas possibilidades, consciente de sua finitude e de sua responsabilidade perante suas escolhas, capaz de inventar e cuidar de sua própria existência mediante a práxis. De acordo com essa visão, a psicopatologia vai se manifestar por meio de uma vivência de sofrimento em que a pessoa se sente vítima e presa a um destino sombrio e a uma existência destituída de realizações gratificantes e prazerosas. Sem liberdade de escolha, a pessoa vive a sensação de estar encurralada pelas circunstâncias da vida, sentindo-se impotente para modificá-las, submetendo-se a elas, num sacrifício alienante e inevitável.

Angerani-Camon (2000) defende que as decisões importantes que afetam a vida futura da pessoa raramente são tomadas sem alguma forma de depressão mental, e é um lugar comum da crítica social contemporânea afirmar que o homem moderno procura por todos os meios fugir a essa forma de tensão, delegando aos outros a responsabilidade por sua tomada de decisão, é a angustia da liberdade, um sentimento gerado pelo ato inevitável da escolha.

Ainda de acordo com Erthal (1991), essa abordagem tem como objetivo o resgate da liberdade de poder utilizar suas próprias capacidades para existir. O indivíduo precisa compreender à utilização de sua própria capacidade de optar livremente e responsavelmente. Aprende a viver em harmonia, enxergando as possibilidades habitualmente bloqueadas por seus sintomas defensivos, o cliente prepara-se, de forma significativa, para a comunicação consigo mesmo e com o outro.

\section{Comportamental}

Segundo Lobato, Lopes e Lopes (2006), a terapia comportamental propõe sua intervenção clínica pautada na avaliação precisa do comportamento-alvo e de sua interdependência com outros comportamentos, na especificação da descrição do comportamento, nas dimensões e funções do comportamento, na história de reforçamento e na frequência e ocorrência dos comportamentos desadaptativos. E é por meio das relações funcionais entre os estímulos do ambiente e as respostas das pessoas que se pode planejar as mudanças comportamentais. Os autores ainda assinalam que a abordagem comportamental é empregada no sentido de se entender por que aquele indivíduo, vivendo dentro de certas situações e num dado momento, apresenta aqueles comportamentos e os mantêm. Desse modo, o terapeuta comportamental busca descobrir as causas que originaram aqueles comportamentos desadaptativos, assim como os fatores envolvidos na sua manutenção.

Na terapia analítico-comportamental, todo comportamento, seja ele adequado ou inadequado, tem uma funcionalidade no ambiente em que ocorre. Assim, como são inúmeras as variáveis que interagem com o indivíduo e que podem estar contribuindo tanto para a aquisição quanto para a manutenção de qualquer tipo de comportamento, a análise de contingência deve levar em conta todos os ambientes do sujeito, inclusive as formas de relacionamento deste (Ingberman \& Salvo, 2007).

$\mathrm{Na}$ terapêutica da análise do comportamento, é preciso identificar em sua história de vida as relações entre contingências ambientais e variáveis comportamentais, para que assim o indivíduo possa compreender que seus comportamentos têm efeito no meio e que existem outras formas de comportamentos para obter reforçamento positivo (Nahmias \& Keuffer, 2001).

Para Abreu (2006), a depressão resulta da redução na taxa de respostas contingentes ao reforçamento positivo. E seriam três formas pelas quais a redução na taxa de respostas contingentes ao reforçamento positivo seria capaz de dar-se: por meio da perda na efetividade reforçadora dos eventos que antes serviam de reforçadores positivos; na mudança do ambiente do indivíduo; e no baixo repertório de habilidades para acessar os reforçadores positivos.

Ferster (1977) assinala que a redução da probabilidade de efetuar determinadas atividades que antes eram reforçadoras e um aumento de comportamentos de fuga e esquiva, associado a um aumento da latência de suas respostas, são características bem marcantes no sujeito depressivo. O depressivo está sujeito a penas e sanções do meio, diminuindo no ambiente a probabilidade de ser reforçado. As variáveis que influenciariam dado repertório comportamental seriam a baixa frequência de reforçamento positivo associada ao aumento da frequência do reforçamento negativo.

Outro fator importante na análise do comportamento depressivo é a capacidade que o sujeito 
tem em expressar e identificar seus sentimentos. A expressividade emocional é um elemento-chave no processo, pois parece estar envolvido em vários outros comportamentos, como estabelecimento de vínculos afetivos, autoestima, autocontrole e adaptação social, considerando-se que a maior parte de quem apresenta problemas emocionais e ou comportamentais também apresenta dificuldades de identificar e expressar o que sente em relação às pessoas e/ou situações (Moura \& Venturelli, 2004).

Fester (1977) também comunga com essa vertente e assegura que mudanças expressivas no ambiente e determinadas perdas são capazes de gerar uma diminuição no comportamento, por falta de reforçamento ou deficiência do indivíduo para lidar com situações novas.

\section{Metodologia}

Após a revisão de literatura, a coleta de dados foi iniciada tendo previamente sido aprovada pelo comitê de ética. A pesquisa de campo foi realizada nas cidades de Cascavel, Corbélia, Realeza, e Toledo, PR, no período do mês de agosto. Esta pesquisa é do tipo qualitativa, em que os dados obtidos por meio das respostas dos profissionais foram comparados com o referencial teórico levantado, a fim de ter ciência se haveria concordância ou não entre as duas fontes. Para o levantamento dos dados foi utilizado um questionário do tipo aberto, contendo 15 perguntas agrupadas conforme os objetivos. A entrevista foi realizada com 20 psicólogos clínicos, de ambos os sexos, escolhidos aleatoriamente em cada cidade.

\section{Discussão e análise dos dados}

A partir da análise deste tema tão complexo que é a depressão infantil, evidenciam-se as diferentes linhas de discussão que podem ser tomadas, os diferentes olhares sobre este assunto e quão novo é esse objeto de estudo. É a partir deste tema, ainda recente, que se levantou a hipótese de realizar este trabalho, com o intuito de pesquisar quais as linhas teóricas que debatem este tema e qual a visão dos profissionais de psicologia diante dele.

A análise demonstrou as diferentes formas de ver a depressão, que variam de acordo com a abordagem teórica escolhida e também com o critério de diagnóstico utilizado (uns acreditam que os critérios de diagnóstico são os mesmos para adultos e crianças, outros entrevistados creem que há critérios diferenciados de uma faixa etária para outra); os muitos profissionais entrevistados não trabalharem com crianças; o baixo número de pacientes que são diagnosticados como depressivos (que se deve a vários fatores, tais como: algumas abordagens não percebem a depressão como causa principal, o baixo número de crianças depressivas); essas crianças serem encaminhadas ao consultório psicológico principalmente pelos pais, professores e médicos; as principais queixas que levam as crianças ao consultório serem de problemas de comportamento, queixas de dificuldade de aprendizagem, diminuição das atividades de interesse, entre outros; que os principais sintomas associados à depressão pelos questionados são: comportamentos de choro frequente, baixa autoestima, relacionamento pessoal enfraquecido, sentimento de tristeza e solidão acentuados, dores de cabeça constantes, quadro de colesterol elevado; quantas dessas crianças apresentaram pais com distúrbios psiquiátricos; o baixo número de casos de ideação suicida e, por final, como este tema é novo e suas terminologias são mais comumente usadas pela psiquiatria, a urgência da necessidade de um maior envolvimento e debate sobre este assunto.

$\mathrm{Na}$ primeira questão, que objetivava saber como os profissionais conceituavam depressão, percebeu-se o quanto é diferente a forma de conceituá-la em cada entrevista. Os profissionais entrevistados divergem, é o que se observou nas respostas. Ao perguntar para Roberta ${ }^{1}$ o que ela entendia por depressão infantil, a resposta foi a seguinte: "como nomeação feita às pressas pela medicina, quando se tem tempo para diagnóstico criterioso, e principalmente para ouvir a criança, descobre-se que a alteração de humor na verdade é apenas um sinal, mas que tem outras causas subjacentes", já Katia defende que "é uma alteração comportamental no responder do individuo. De maneira geral, o organismo passa a diminuir a frequência de suas respostas frente a situações

1 Os nomes utilizados para os profissionais entrevistados são fictícios. 
que anteriormente respondia normalmente. Esse responder alterado produz consequências diversas, como sentimento de isolamento social, apatia, tristeza, etc." e Cristiane coloca ainda um terceiro ponto de vista ao afirmar que a depressão é: "entristecimento, incapacidade da criança ser aquilo que o outro deseja dela (familiares)".

E por meio dessas maneiras diversificadas de vivenciar a depressão se justificam os variados instrumentos de intervenção utilizados por abordagem, variando desde ludoterapia até utilização da fala como alívio dos sintomas e entrevistas com os pais e educadores. Josefina coloca que o instrumento que utiliza é a "ludoterapia psicanalítica", Carla em compensação defende que é necessário ter como instrumento para uma boa intervenção a "entrevista com a familia, em especial com os pais e/ ou educadores; visita à escola; contato direto com a criança. Quando preciso de um dado, a utilização do inventário de Beck para depressão".

Essas múltiplas formas de significar a depressão trazem a dificuldade de trabalhar com essas diversas respostas. Mais um percalço, ao levantar esses dados, foi o pequeno número de profissionais que possuem como alvo de atendimento a clientela infantil. Ao deparar-se com esse entrave à pesquisa, tendo em vista o baixo número de terapeutas que atendem crianças, obteve-se pouca informação sobre essa temática. Todavia, os psicólogos que contribuíram com a pesquisa defendem a valorização da maturidade da criança para referir-se aos sintomas da depressão infantil. Isso confirma o que Spitz (1998), citado por Buzaid et al. (2005), diz: a depressão no adulto e na criança não são comparáveis, pelo contrário, são entidades psiquiátricas completamente diferentes. Os sintomas são similares, mas o processo subjacente é diferente.

Outro fator relevante foi o baixo número de crianças que vêm ao consultório psicológico e são diagnosticadas com depressão, isso ocorre, entre outras coisas, pelas abordagens terem formas diferentes de ver um mesmo fato e muitas delas não trabalharem com o mecanismo do diagnóstico, não visualizarem a depressão como causa principal, apenas como sintoma de angústia, o profissional não comungar com os critérios de diagnóstico presentes no referencial teórico deste artigo, o baixo número de crianças depressivas (o que é um dado extremamente positivo) e as terminologias que são mais comumente usadas pela psiquiatria.

Isso nos permite dizer que se houvesse maior abrangência do tema, e uma clareza no uso da terminologia própria da psicologia, facilitaria o entendimento do assunto dentre as diferentes abordagens.

Outro dado encontrado é que as crianças são encaminhadas principalmente pelos pais, professores e médicos (pediatra, neurologista, clínico geral) o que pode ser visto na fala de Taiane: "normalmente essas crianças vêm ao consultório depois de terem passado pelo clínico geral, pediatra ou algum especialista que nem sempre soluciona oproblema e encaminha pro consultório. Casos que são encaminhados pela escola, normalmente são casos mais leves".

As principais queixas que levam as crianças ao consultório psicológico, segundo os psicólogos entrevistados são: problema de comportamento; queixa da dificuldade de aprendizagem; diminuição das atividades de interesse; TDAH, déficit em habilidades sociais, exigência de suas capacidades; problemas alimentares; dificuldade de relacionamento; perda do sono. O que é bem expresso por Taiane: "diminuição da atividade e do interesse, queda no rendimento escolar, perda da atenção, distúrbios do sono, aparecimento de condutas agressivas, autodepreciação, perda de energia física e mental, aumento da sensibilidade (chora por qualquer coisa), cansaço matinal', e Lais: "dificuldades de comportamentos (transtorno de conduta), transtornos alimentares e queixas escolares de baixo rendimento". Andriola e Cavalcante (1999) e Barbosa e Lucena (1995) também comungam com o referido acima e apontam como principais comportamentos que caracterizam a depressão infantil os sintomas físicos, seguidos por ansiedade, fobias, agitação psicomotora ou hiperatividade, irritabilidade, entre outros. E é apoiado por Fichtner (1997), ao afirmar que esse prejuízo no desenvolvimento infantil acarretado pela depressão infantil pode ser em nível físico, cognitivo, psicomotor e psicossocial, prejudicando inclusive as habilidades necessárias para a aprendizagem.

Junto com as principais características que levam as crianças ao consultório psicológico, percebeu-se que as comorbidades apresentadas por elas eram, em um número maior, comportamentos de choro frequente, baixa autoestima, relacionamento pessoal enfraquecido, sentimento de tristeza e solidão acentuados, dores de cabeça constantes, quadro de colesterol elevado. Josefina e Taiane trazem em seu posicionamento esses dados e deixam claro por meio de suas vivências que estão de acordo com o que diz a teoria, que, como Bahls (2002) assegura, a depressão infantil costuma apresentar altas taxas de comorbidade, as mais comuns são transtorno de ansiedade, transtorno de conduta, transtorno 
desafiador opositivo e transtorno de déficit de atenção. Segundo diz Josefina: "baixa autoestima, baixa autoconfiança, relacionamento interpessoal enfraquecido, sentimento de tristeza e solidão acentuadas, sentimento de menos amado, sem importância, preocupação com aptidões familiares, dificuldade no relacionamento familiar, baixo rendimento acadêmico"; e Taiane: "dificuldades escolares e ou de relacionamento, queixas somáticas (dores de cabeça constantes, houve dois casos com quadro de colesterol elevado em que o endocrinologista encaminhou pra psicoterapia)".

Mais um fator que merece destaque é a ausência de casos de ideação suicida por parte das crianças. O que pode ocorrer por realmente não existir ou, então, como afirmam Calderano e Carvalho (2005), pelos meios de tentativa de suicídio por parte das crianças serem os mais variados possíveis e não serem tão eficazes quanto os realizados por adolescentes e adultos, as suas atitudes acabam por serem vistas como coisa da infância.

\section{Consideraçóes finais}

Ficou claro que a depressão infantil ainda é um tema recente e que precisa ser visto, como defendem Andriola e Cavalcante (1999), trata-se de uma perturbação orgânica que engloba variáveis biopsicossociais. Eque, acima de tudo, como afirmam Barbosa e Lucena (1995), é uma entidade única e pertinente a cada faixa etária.

A depressão tem diferentes maneiras de ser vista, variando de uma linha teórica para outra, como no caso da psicanálise, em que a depressão é considerada como luto, inerente ao ser humano, que terá que passar por isso por conta das perdas que também são inatas. Ela não deve ser caracterizada enquanto estrutura psíquica por se tratar de um estado próprio da constituição do aparelho psíquico, possibilitando declarar que tal quadro caracteriza $O$ humano. Portanto, para o diagnóstico em psicanálise não se utiliza o conceito "depressão infantil".

Já a existencial fenomenológica, de acordo com Erthal (1991), conceitua o indivíduo como uma pessoa concreta, única, livre e realizadora de si mesma, rebelde, portanto, a enquadramentos diagnósticos e que, então, precisa compreender a utilização de sua própria capacidade de optar livremente e responsavelmente. Aprender a viver em harmonia, enxergando as possibilidades habitualmente bloqueadas por seus sintomas defensivos, preparando-se, de forma significativa, para a comunicação consigo mesmo e com o outro e com um olhar totalmente dessemelhante que a comportamental assegura, de acordo com Nahmias e Keuffer, (2001), como sendo advinda da diminuição na frequência de reforçamento positivo que pode ser mantida por vários fatores.

Conclui-se que o debate sobre a depressão infantil tem maior abrangência e clareza no uso da terminologia própria da psicologia, quando se consideram o entendimento dos conceitos das diferentes abordagens teóricas no campo da psicologia. A congruência entre os dados trazidos pelos profissionais de psicologia entrevistados e o referencial teórico levantado neste artigo sobre a depressão infantil também só pode ser compreendida ao considerar cada posicionamento a partir do ponto de vista teórico que cada profissional possui. Este tema não se esgota, pois compreender a depressão infantil é fundamental na formação profissional dos psicólogos que trabalham com crianças.

\section{Referências}

Abreu, P. R. (2006). Terapia analítico-comportamental da depressão: Uma antiga ou uma nova ciência aplicada? Revista de Psiquiatria Clínica, 33, 322. Recuperado em 1 dez. 2009, em http://www.hcnet.usp.br/ipq/ revista/vol33/n6/322.html

Andriola, W. B., \& Cavalcante, L. R. (1999). Avaliação da depressão infantil em alunos da pré-escola. Psicologia: Reflexão e Crítica, 12(2), Recuperado em 7 ago. 2009, em http://www.scielo.br/scielo. php?pid $=$ S0102- $9721999000200011 \&$ script $=$ sci_ arttext\&tlng $=$ pt.

Angerani-Camon, A. V. (2000). Angústia e psicoterapia. São Paulo: Casa do Psicólogo.

Angerami-Camon, A. V. (2004). O atendimento infantil na ótica fenomenológica existencial. São Paulo: Afiliada.

Assumpção Jr., F. B. (1992). Depressão na infância. Pediatria Moderna, 28(4), 323-8.

Assumpção Jr., F. B. (1996). Transtornos afetivos da infância e adolescência. São Paulo: Lemos.

Assumpção Jr., B. F., \& Kuczynski, E. (2004). Diagnóstico diferencial da depressão. In M. N. Baptista. Suicídio e depressão. Rio de Janeiro: Guanabara Koogan. 
Bahls, S-C. (2002). Aspectos clínicos da depressão em crianças e adolescentes. Jornal de Pediatria, 78(5). Recuperado em 9 ago. 2009, em http:/ /www.scielo. br/pdf/jped/v78n5/7805359.pdf

Barbosa, G. A., \& Lucena, A. (1995). Depressão infantil. RNIA, 3(2), 23-30. Recuperado em 10 ago. 2009, em http://www.psiquiatriainfantil.com.br/revista/ edicoes/Ed_03_2/in_07_07.pdf

Bowlby, J. (1998). Perda, tristeza e depressão. São Paulo: Martins Fontes.

Buzaid, A., Cunha, B. F. V., Romano, B. W., \& Watanabe, C. E. (2005). Depressão na infância e adolescência: Revisão bibliográfica. Revista Sociedade de Cardiologia, 15(3). Recuperado em 14 ago. 2009, em http://www.socesp.org.br/revistasocesp/edicoes/ volume15/pdf/n03suplemento.pdf.

Calderano, R. S. S., \& Carvalho, C. V. (2005). Depressão na infância: Um estudo exploratório. Psicologia em estudo, 10(2), 181-189. Recuperado em 8 ago. 2009, em http://www.scielo.br/pdf/pe/v10n2/ v10n2a04.pdf

Erthal, T. C. S. (1991). Ser neurótico: Desencontros na psicoterapia e na vida. In T. C. S. Erthal. Terapia vivencial: Uma abordagem existencial em psicoterapia. Rio de Janeiro: Vozes.

Fichtner, N. (1997). Transtornos mentais da infância e da adolescência: Um enfoque desenvolvimental. Porto Alegre: Artmed.

Ferster, C. B. (1977). Depressão clínica. In C. B. Ferster, S. Culbertson, \& M. C. P. Boren. Princípios do comportamento. São Paulo: Hucitec.

Freud, S. ([1915/1917] 1986). Luto e melancolia. Rio de Janeiro: EBSB; Imago.

Ingberman, Y. K., \& Salvo, C. G. (2007). Terapia analíticocomportamental infantil: um estudo de caso. Anais I Encontro Paranaense de Análise do Comportamento, 2007. Recuperado em 27 out. 2009, em http:// www.epac.psc.br/anais/2007/paineis/21.doc

Lage, A., \& Monteiro, K. (2007). Depressão - uma 'psicopatologia' classificada nos manuais de psiquiatria. Psicologia: Ciência e Profissão, 27(1). Recuperado em 13 ago 2009, em http://scielo. bvs-psi.org.br/scielo.php?script=sci_arttext\&pi $\mathrm{d}=$ S1414-98932007000100009
Lobato, G. R., Lopes, R. F. F., \& Lopes E. J. (2006). Algumas considerações sobre o uso do diagnóstico classificatório nas abordagens comportamental, cognitiva e sistêmica. Psicologia em Estudo, 11(1), 45-54. Recuperado em 1 dez. 2009, em http://www. scielo.br/pdf/pe/v11n1/v11n1a06.pdf

Miller, J. A. (1987). A psicanálise e a psiquiatria. FALO: Revista do Campo Freudiano, 1, 133-127.

Moura, C. B., \& Venturelli, M. B. (2004). Direcionamentos para a condução do processo terapêutico comportamental com crianças. RBCC, 6(1), 17-30. Recuperado em 27 out. 2009, em http://scielo.bvs-psi.org.br/ $\mathrm{pdf} / \mathrm{rbtcc} / \mathrm{v} 6 \mathrm{n} 1 / \mathrm{v} 6 \mathrm{n} 1 \mathrm{a} 03 . \mathrm{pdf}$.

Nahmias, T. A., \& Keuffer, A. R. P. (2001). Depressão infantil: Uma análise comportamental. Lato \& Sensu, Belém, 2(4), 5. Recuperado em 31 out. 2009, em http://www.nead.unama.br/site/bibdigital/pdf/ artigos_revistas/58.pdf

Nakamura, E., \& Santos, J. Q. (2007). Depressão infantil: Abordagem antropológica. Revista Saúde Pública, 41(1), 53-60. Recuperado em 20 out. 2009, em http://www.scielo.br/pdf/rsp/ nahead/5092.pdf

Quinet, A. (1993). As 4+1 condições de análise. Rio de Janeiro: Jorge Zahar.

Rodrigues, M. J. S. (2000). O diagnóstico da depressão. Psicologia USP, 11(1). Recuperada em 5 nov. 2009, em http://www.scielo.br/scielo.php?pid=S010365642000000100010\&script $=$ sci_arttext\&tlng $=$ es

Spitz, R. A. (2004). O primeiro ano de vida. São Paulo: Martins Fontes.

Tenório, C. M. D. (2003). A psicopatologia e o diagnóstico numa abordagem fenomenológica-existencial. Ciências da Saúde, 1(1), 31-44.

Recebido: $14 / 12 / 2009$ Received: $12 / 14 / 2009$

Aprovado: 19/05/2010 Approved: 05/19/2010 